\title{
Probabilistic Measures of Earthquake Effects on Fire Performance of Tall Buildings
}

\author{
N. Elhami Khorasani \\ University at Buffalo, Buffalo, NY, U.S.A.
}

T.Gernay

University of Liege, Liege, Belgium

M. Garlock

Princeton University, Princeton, NJ, U.S.A.

\begin{abstract}
Cascading multi-hazard events, such as fires following an earthquake, can trigger progressive collapse of structures. Risk or the probability of reaching a limit state after an extreme event is related to (a) the probability of occurrence of the hazard, and (b) the probability of reaching the limit state given the hazard. In this paper, earthquake effects on fire performance of tall buildings in a community are studied. First, the probability of fire ignition due to an earthquake is modeled based on historical data and properties of the built environment. In the second step, the effect of earthquake on structural fire performance of a steel frame is studied using system level probabilistic approaches. The results show that the earthquake does not increase the probability of reaching different limit states under fire, however, post earthquake fire can increase the drift demand on columns located on the perimeter of the structure, and may cause instability.
\end{abstract}

\section{INRODUCTION}

A resilient city or community is one that can continue its functions after an extreme event (Hay et al., 2014). If a city has to stay functional after a hazard and recover from the event, then the performance of individual elements, connectivity of critical infrastructure elements in the system, and cascading effects on the system should be incorporated in the design of the community. Meanwhile, as historical events show, the likelihood of a fire event is typically amplified following seismic events due to an introduction of available fuel and ignition sources such as ruptured utility lines (Elhami Khorasani \& Garlock, 2015). On the other hand, active and passive fire protection system can also be compromised by seismic shocks.

Similar to earthquake engineering, risk of fire cannot be avoided, and given the uncertainties, probabilistic performance-based guidelines should be available as an option for design engineers. There have been recent studies by researchers in generating probabilistic approaches for fire engineering (De Sanctis el al. (2011), Guo et al. (2013), Lange et al. (2014), Guo and Jeffers (2014)). Despite the steps taken to develop probabilistic guidelines, there still does not exist a comprehensive, systematic, and practical framework to evaluate structures under fire and fire following earthquake (FFE), incorporating uncertainties in the process and considering various performance criteria. In the case of FFE at the community level, the gap in knowledge is even deeper.
Previous research on structural performance for post-earthquake fires had typically studied the problem in separate programming environments for seismic and thermal analyses (Della Corte et al., 2003; Zaharia \& Pintea, 2009; Ronagh \& Behnam, 2012). The shortcoming in such an approach is that switching between programs to complete seismic and thermal analyses requires certain idealizations, such as disregarding material and structural degradation after the earthquake, which would reduce the effectiveness of the modeling results.

This paper proposes a probabilistic framework that can be expanded to evaluate the response of a community of buildings to fire following earthquake. First, a model to predict the probability of ignition in a building due to an earthquake is discussed $\left(P_{I g}\right)$. Given an ignition in a building, the probability of the structure exceeding certain limit states must be evaluated in order to quantify the expected damage $\left(P_{\text {damage }} \mid\right.$ Ignition $)$. The total probability of damage can then be calculated using Eq. 1 and conditional probability.

$$
P_{\text {damage }}=P_{\text {Ig }} \times P_{\text {damage }} \mid \text { Ignition }
$$

\section{IGNITION MODEL}

\subsection{Proposed FFE Model}

The authors have developed a probabilistic ignition model (Elhami Khorasani et al., 2015c) based on seven historical earthquake events, all of which oc- 
curred in California, U.S.A., between 1983 and 2014: 1983 Coalinga, 1984 Morgan Hill, 1986 North Palm Spring, 1987 Whittier Narrows, 1989 Loma Prieta, 1994 Northridge, and 2014 Napa. The model relates the probability of ignition to the peak ground acceleration $(P G A)$, type of building material, and the main features of the environment in which the buildings are located (i.e. the total square footage and the population density). The proposed ignition model can be used to estimate the expected number of post-earthquake ignitions for a region.

In order to use the model, an inventory of census tracts for the region of study including population density $(P D)$, total square footage of the buildings $(S F)$, number of wood buildings $\left(N_{W}\right)$, number of mobile homes $\left(N_{M H}\right)$, and number of buildings made of non-combustible material $\left(N_{N C}\right)$ should be compiled. Eq. 2 can be used to calculate the probability of ignition in a census tract given the $P G A$ values.

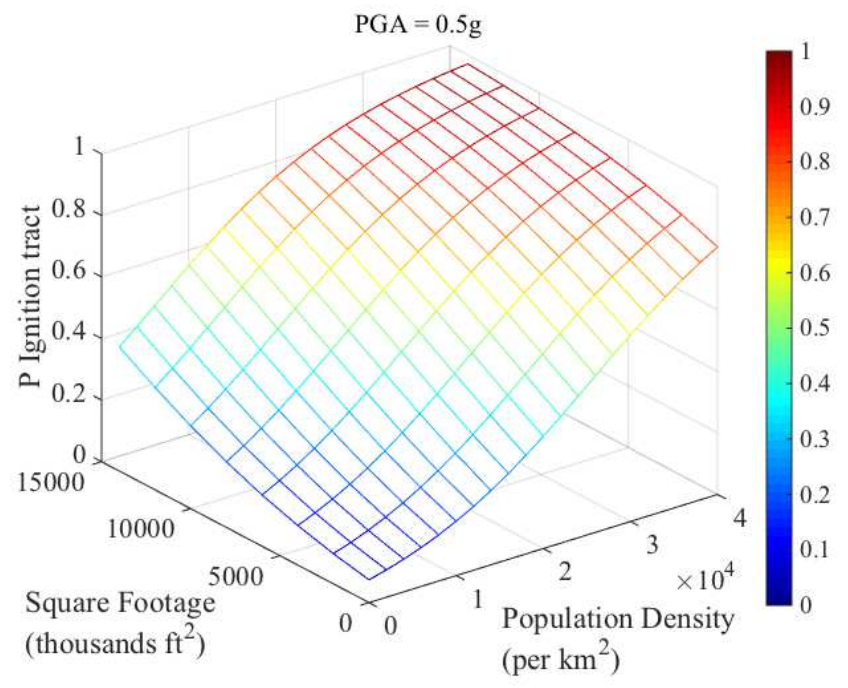

Figure 1: Probability of ignition for a census tract based on Eq. 1 for $P G A$ of $0.5 \mathrm{~g}$

$$
\begin{aligned}
& P_{\text {lg_tract }}=\frac{\exp \left(-6.755+8.463 \times P G A+98.4 \times 10^{-6} \times P D+152.3 \times 10^{-6} S F\right)}{1+\exp \left(-6.755+8.463 \times P G A+98.4 \times 10^{-6} \times P D+152.3 \times 10^{-6} S F\right)} \\
& P_{l g_{-} \text {tract }}=1-\left[\left(1-0.471 P_{l g}\right) \mid P G A\right]^{N_{W}} \times\left[\left(1-1.0 P_{l g}\right) \mid P G A\right] \\
& N_{M H} \times\left[\left(1-0.411 P_{l g}\right) \mid P G A\right] \\
& \text { Number of ignitions }=\sum_{i=1}^{m}\left[N_{W C} \times\left(0.471 P_{l g}\right)+N_{M H} \times\left(1.0 P_{l g}\right)+N_{N C} \times\left(0.411 P_{l g}\right)\right]_{i}
\end{aligned}
$$

Fig. 1 shows the probability of ignition in a census tract for $P G A$ of $0.5 \mathrm{~g}$. Given the probability of ignition in each census tract and the number of each building types, probability of ignition $\left(P_{I g}\right)$ for each building type can be calculated from the relationship in Eq. 3. Finally, the expected number of ignitions in " $m$ " census tracts equals to the sum of probabilities of ignitions for all buildings in the census tracts, as shown in Eq. 4.

\subsection{Validation}

The proposed ignition model is validated by estimating the number of ignitions based on the available FFE historical events. The number of ignitions from the proposed model in Table 1 is compared with the actual reported number of ignitions, and with a validation study by HAZUS (NIBS, 1999) and (Scawthorn et al., 2005). HAZUS provides a range for the number of ignitions as the program suggests running the analysis a number of times to capture uncertainties in the process. Overall, the proposed probabilistic model in this work captures the number of fire events after an earthquake reasonably well, given the level of uncertainty that exists in the community response. In addition, the proposed model has the advantage of providing the breakdown in the number of ignitions for different considered building types.
Table 1: Validation study for ignition model

\begin{tabular}{l|cc|cccc}
\hline \multirow{2}{*}{ Earthquake } & \multicolumn{5}{|c}{ Number of Ignitions } \\
\cline { 2 - 7 } & \multirow{2}{*}{ Actual } & HAZUS & \multicolumn{5}{|c}{ Proposed Model } \\
\cline { 4 - 7 } & & & Total & W & MH & NC \\
\hline Coalinga & 3 & 1 & 0.5 & 0.5 & 0 & 0 \\
Morgan Hill & 6 & N/A & 4 & 4 & 0 & 0 \\
N. Palm Spring & 1 & N/A & 3 & 2 & 1 & 0 \\
Whittier & 20 & $33-43$ & 32 & 27 & 1 & 4 \\
Loma Prieta & 36 & $14-38$ & 27 & 22 & 2 & 3 \\
Northridge & 82 & $72-101$ & 90 & 75 & 3 & 12 \\
Napa & 6 & N/A & 3 & 3 & 0 & 0 \\
\hline TOTAL & 154 & N/A & $\mathbf{1 6 0}$ & $\mathbf{1 3 4}$ & $\mathbf{7}$ & $\mathbf{1 9}$ \\
\hline
\end{tabular}

\section{SYSTEM LEVEL DAMAGE STATE}

This section provides a probabilistic methodology to evaluate performance of a building subject to fire following earthquake. The methodology is applied to a case study, a 9-story steel building, and sample of results are provided.

\subsection{Methodology}

The following steps to perform post-earthquake fire analysis of a Moment Resisting Frame (MRF) are performed:

(1) Select an earthquake scenario, 
(2) Select a fire scenario,

(3) Perform seismic structural analysis,

(4) Change model constraints to allow for thermal expansion,

(5) Perform structural-fire analysis.

Steps 1, 2, and 5 involve uncertainties in defining demand and capacity parameters. Following a routine Monte Carlo Simulation (MCS), the process can be repeated multiple times to incorporate the uncertainties.

Extensive literature exists in earthquake engineering, and previously proposed probabilistic models for defining ground motions can be used in Step 1 (Shome \& Cornell, 1999), (Pant, 2009). Defining a fire scenario is mainly related to the fire load density, which depends on the occupancy type. As an example, Elhami Khorasani et al. (2014) have developed a probabilistic fire load density $(q)$ model for office buildings based on survey results from a study in the U.S.A. The model for $q$ includes the effect of room size $A_{f}$ on the fire load density as shown in Eq. 5 , where $q$ is in units of $\mathrm{MJ} / \mathrm{m}^{2}, A_{f}$ is the room size in $\mathrm{m}^{2}, \varepsilon$ is a random variable that follows the standard normal distribution, and the term $0.5712 \varepsilon$ is the model error. Eq. 5, or similar models, can be used in Step 2 to quantify $q$. Given a fire load density, the fire temperature-time curve can be obtained for Step 2 following procedures such as parametric temperature-time curves in Eurocode1 (CEN, 2002).

$$
q=\exp \left[6.591-0.0047\left(A_{f} \times 10.76\right)+0.5712 \varepsilon\right]
$$

In performing structural-fire analysis of steel structures in Step 5, yield strength and modulus of elasticity of steel are two important parameters that involve uncertainty at elevated temperatures. Elhami Khorasani et al. (2015a) used the available data in the literature to develop probabilistic models for normalized yield strength and modulus of elasticity of steel at elevated temperatures $\left(k_{y, 2} \%\right.$, $T$ and $k_{E, T}$ respectively). The models (Eqs. 6 to 8) were developed using a logistic function, where $k_{y, 2 \%, T}^{\wedge}$ is the normalized value of yield strength from Eurocode 3 (CEN, 2001), $T$ is the temperature in Celsius, and $\varepsilon$ is a random variable that follows the standard normal distribution.

$$
K_{y, 2 \%, T}=1.7 \frac{e^{\left[\operatorname{logit}\left(\hat{K}_{y, 2 \%, T}^{*}\right)+0.412-0.81 \times 10^{-3} \times T+0.58 \times 10^{-6} T^{1.9}+0.43 \times \varepsilon\right]}}{1+e^{\left[\operatorname{logit}\left(\hat{K}_{y, 2 \%, T}^{*}, T\right)+0.412-0.81 \times 10^{-3} \times T+0.58 \times 10^{-6} T^{1.9}+0.43 \times \varepsilon\right]}}
$$

where in Eq. $6 \operatorname{logit}\left(\hat{k}_{y, 2 \%, T}^{*}\right)=\ln \left[\frac{\left(\hat{k}_{y, 2 \%}, T+10^{-6}\right) / 1.2}{1-\left(\hat{k}_{y, 2 \%, T}+10^{-6}\right) / 1.2}\right]$

$$
K_{E, T}=1.1 \frac{e^{\left(2.54-2.69 \times 10^{-3} \times T-2.83 \times 10^{-6} T^{2}+0.36 \times \varepsilon\right)}}{1+e^{\left(2.54-2.69 \times 10^{-3} \times T-2.83 \times 10^{-6} T^{2}+0.36 \times \varepsilon\right)}}
$$

Finally, the structure should be analyzed for different Engineering Design Parameters (EDP) related to beams, columns, or connections, and the corresponding limit states such as beam mechanism, column yielding, or connection failure.

\subsection{Case study}

In this paper, performance of a prototype 9-story steel moment resisting frame (MRF) under postearthquake fire scenarios are studied, where the MRF has gone through nonlinear seismic analysis and may have permanent residual deformations before the fire starts. The MRF is located in downtown Los Angeles and has plan and elevations that are designed based on SAC buildings (SAC, 2010) but considered only for stiff soil. The frame is designed according to ASCE7-10 specifications (2010). Fig. 2 shows the analytical model for the 9-story frame in OpenSees, and includes the design of the MRF. OpenSees, with the recently added thermal module (Jiang et al., 2015), is used to perform both nonlinear seismic and fire analysis. The thermal module was modified by Elhami Khorasani et al. (2015b) to enhance the thermal analysis by allowing strain reversals and including reliability analysis.

In this study, only one ground motion is selected for Step 1 (i.e., deterministic assumption), while several fire load scenarios considering uncertainties in fire load, and fire location (Step 2) are modeled, and variability in material properties at elevated temperatures (Step 5) are considered. The selected ground motion is the 1989 Loma Prieta, CA earthquake, recorded at station 47381 Gilroy (Array \#3), that is scaled to the Maximum Considered Earthquake. Performance of the frame is analyzed under four different EDPs related to the beam. For each considered EDP, a corresponding limit state is defined as shown in Table 2 and explained as follows:

Table 2. EDPs and the corresponding limit states

\begin{tabular}{|ll|}
\hline EDP & Limit State \\
\hline \hline Plastic hinges & 3 plastic hinges \\
Pseudo-velocity & $0.01 \mathrm{in} / \mathrm{sec}(0.254 \mathrm{~mm} / \mathrm{sec})$ \\
Tension force & $20 \% P_{u}$ of the column \\
Deflection & $L / 20$ \\
\hline
\end{tabular}

(1) Plastic Hinges: In a MRF with moment connections, three plastic hinges in a beam form a mechanism, in which case the beam loses its load carrying capacity and its capacity to provide lateral restraint to the column.

(2) Pseudo Velocity: The pseudo-velocity is calculated as the rate of displacement of the beam. The EDP is defined as the pseudo-velocity of the beam at the beam mid-span. Based on previous studies (Usmani et al., 2003), a limiting value of $0.01 \mathrm{in} / \mathrm{sec}$ is defined for pseudo-velocity of the beam. 


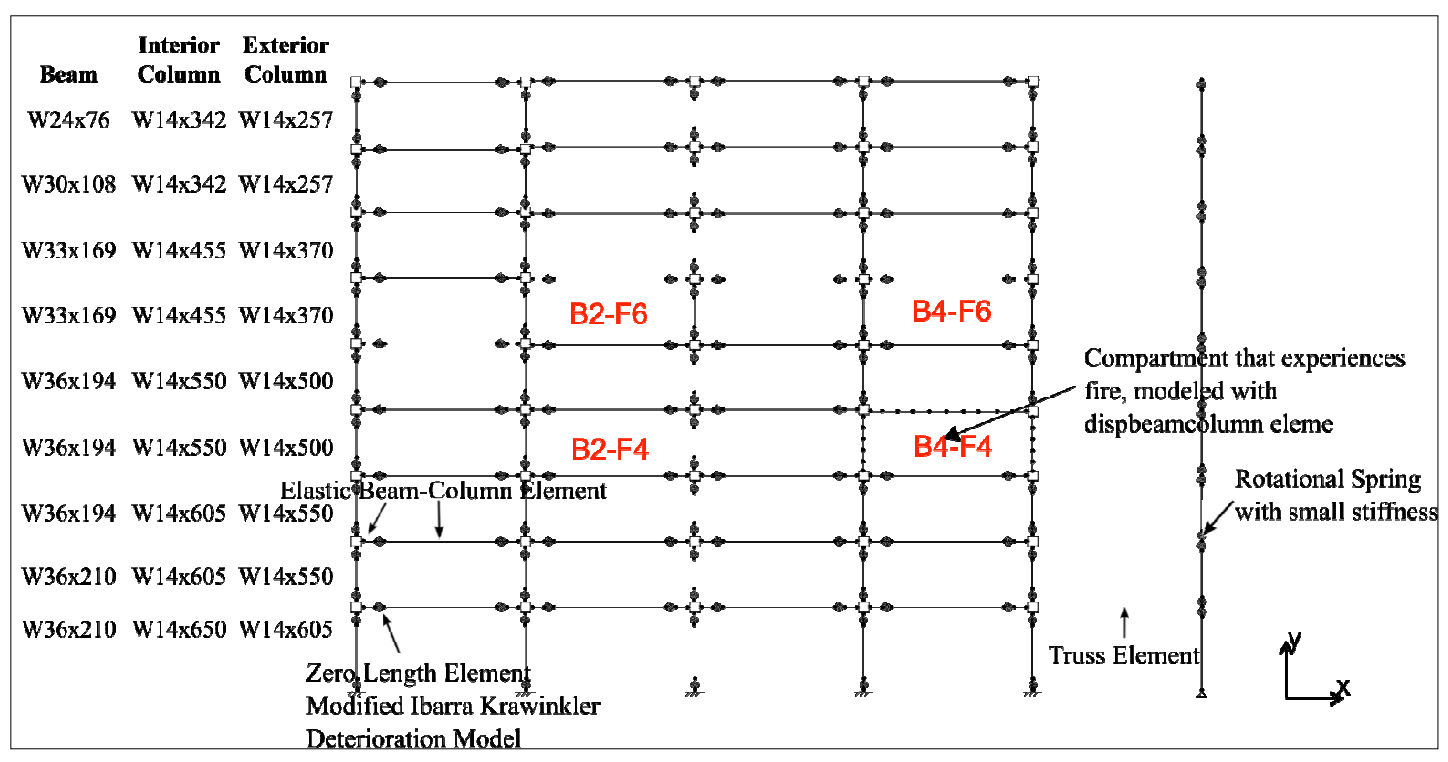

Figure 2: Analytical model of the prototype 9-story MRF in OpenSees and a list of design sections

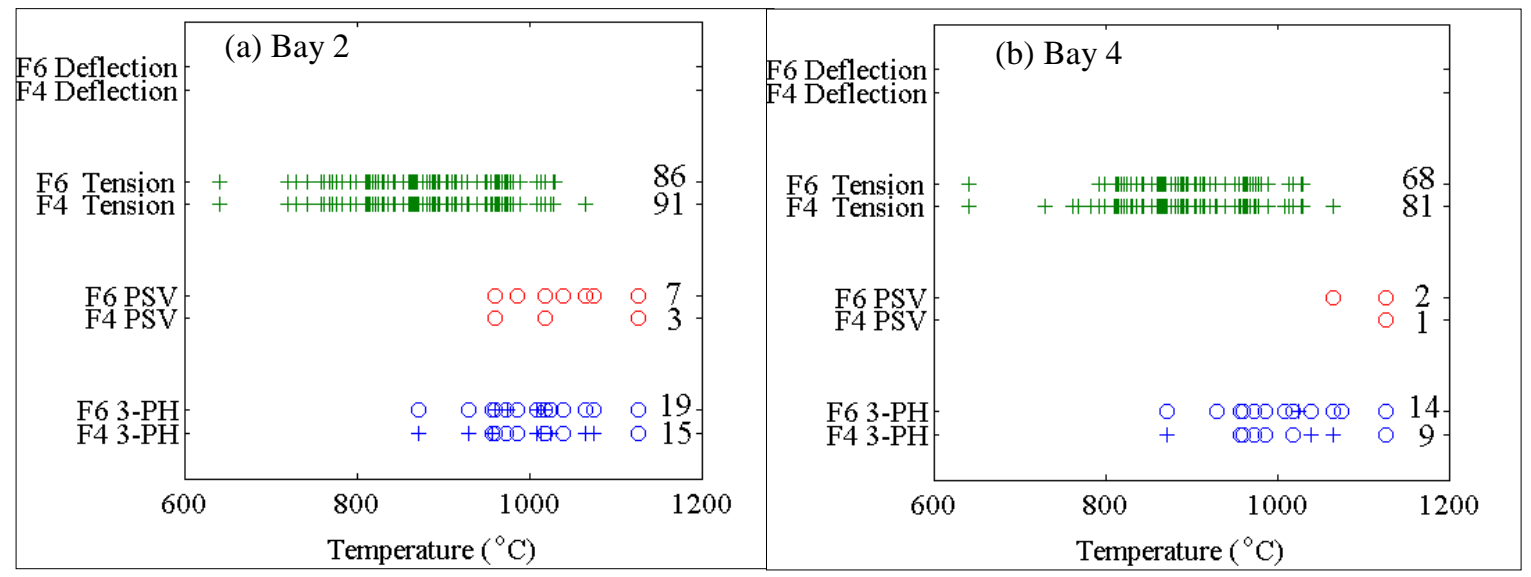

"o" : cases that the program stops converging during the heating phase of fire

"+" : cases that the program continues through cooling phase of fire

Figure 3: Plots of limit states reached for fire following the Gilroy earthquake scenario

(3) Tension Force: Large tension forces can develop in the beam during cooling phase of the fire, and consequently cause connection failure. The finite element model in OpenSees does not capture connection failure. Therefore, based on sample calculations, a limit state of $20 \% P_{u}$ of the column is defined for the maximum tension force in the beam before a connection fails.

(4) Deflections: Excessive deflections can cause instability, damage to non-structural elements, and increase the likelihood of fire spread beyond the compartment. The limit state is defined as $L / 20,(L$ is the span length) (BRE, 2005).

Note that the adopted pseudo-velocity and deflection thresholds are also in line with the European standards (Dumont, 2016).

\subsection{Results}

Fig. 3 shows a sample of results for 100 MCS varying fire load density and steel material properties at elevated temperatures. Fig. 3 identifies the limit states reached under each of the 100 scenarios for fire following the Gilroy ground motion. The plots group results based on the bay under study (Bay 2 and Bay 4), and the two considered floors (Floor 4 and Floor 6). On the right margin of each plot the total number of cases reaching the limit state is indicated. Also, the plots differentiate between the cases that the program stops converging (the analyzing software, OpenSees, can no longer advance the analysis) during the heating phase of fire (circle markers) versus cases that continue through cooling phase of temperature-time curve of fire (plus-sign markers).

Comparing Floors 4 and 6 , the results show that there are more cases that form three plastic hinges in Floor 6 when compared to Floor 4. In addition, results of the simulations showed that the time to form three plastic hinges in compartment B4-F4 is longer for most cases compared to compartment B4-F6. This is similarly true for compartments B2-F4 and B2-F6 (with B2-F4 taking longer). This implies that in majority of cases, it takes longer 
to form three plastic hinges in the fourth floor compared to the sixth floor of the same bay. This is due to the fact that lower floors have stronger beams compared to upper floors (design sections shown in Fig. 2).

Fig. 3 shows that there are more cases that reach PSV limit state in Floor 6 when compared to Floor 4 . In addition, the beams experience more tension limit states in Floor 4 than those on Floor 6. This is attributed to Floor 4 experiencing fewer plastic hinge limit states, therefore more analyses continue to run though the cooling phase in Floor 4 compared to Floor 6, and it is in the cooling phase of the fire that tension failure develops.

Comparing Bays 2 and 4, the results show that there are more cases that form three plastic hinges, reach PSV, and the tension limit states in Bay 2 when compared to Bay 4. This can be explained by the extra restraint and larger axial forces in the interior bays compared to more flexible beams in the exterior bays.

Another important set of results is from comparing the FFE performance of the frame with the corresponding fire-only scenarios where the frame has not experienced any earthquake damage when the fire starts; i.e., the same fire scenarios are introduced to the intact frame. The results for fire-only and FFE scenarios are similar, meaning that the earthquake does not have a significant effect on the considered limit states. However, inter-story drift of floors is the one parameter that is intensified when fire follows the earthquake, meaning that the interstory drift during fire accumulates on the residual drifts after the earthquake. The analysis shows that the exterior bays experience drifts that are larger than the interior bays. In addition, given the less restraint at upper floors, fire causes more drift on Floor 6 than Floor 4. The maximum drift after the earthquake and during the fire may exceed $3 \%$ (in B4-F6). Overall, the earthquake does not increase the probability of reaching a limit state, but it affects the drift values and stability issues during the fire.

\section{FUTURE APPLICATIONS}

Section 3 provided a probabilistic methodology to study performance of a building under FFE. The results from MCS provide the probability of reaching different limit states. The proposed methodology can be used to quantify the performance of different structural types under different fire scenarios and categorize the probability of reaching different limit states into groups based on the level of damage. This leads to the concept of fragility function for fire, which is commonly used in seismic engineering. The authors have recently applied this concept to fire engineering (Gernay et al., 2016) and will extend the framework to fire following earthquake.
The next step in this research is to derive fragility functions for different building types (steel, concrete, etc.) and with different heights (low, medium, and high-rise). Different levels of damage, such as a beam or column damage state can be investigated. This way, $P_{\text {damage }} \mid$ Ignition, that was discussed in Eq. 1. (Sect. 1. Introduction) can be systematically evaluated. Finally, the ignition model, together with fragility functions, can be combined to evaluate resiliency of a community to FFE.

\section{CONCLUSIONS}

This paper provided a probabilistic methodology to (a) measure the probability of fire ignition in a community of buildings, and (b) evaluate probabilistic performance of a building under a fire scenario after an earthquake. The two parts together can be used to assess the performance of a community under fire following earthquake. The developed ignition model was based on historical data and provided a breakdown in the number of ignitions for different building construction types. The results from a case study on performance of a 9-story steel MRF showed that the earthquake does not change the probability of reaching a limit state under fire, however, larger drift values should be expected when fire follows an earthquake, compared to fireonly scenarios.

The case study in this paper focused on the performance of a MRF in a building, assuming that the earthquake damage may increase the vulnerability of the building to fire. However, the MRF was built up of heavy cross sections and the earthquake did not change the fire performance of the frame significantly. Given that the ignition may occur anywhere in the building, and that the gravity frames are generally designed with smaller cross sections, it is notable that the gravity frames can reach limit state much faster than the MRF and may experience considerable damage.

\section{REFERENCES}

1. ASCE. 2010. "Minimum Design Loads for Buildings and Other Structures (ASCE/SEI 7-10)," American Society of Civil Engineers, Reston, VA.

2. BRE: Building Research Establishment Ltd. 2005. "The Integrity of Compartmentation in Buildings During Fire," Project report No. 213140(1).

3. CEN. 2001. "Eurocode3: Design of Steel Structures, Part 1-2: General Rules - Structural Fire Design (ENV 1993-12:2001)," European Committee for Standardization (CEN), Brussels.

4. CEN. 2002. "Eurocode1: Actions on structures, Part 1-2: General actions - actions on structures exposed to fire," European Committee for Standardization (CEN), Brussels: Belgium. 
5. De Sanctis, G., Fischer, K., Kohler, J., Fontana, M., Faber, M. H. 2011. "A probabilistic framework for generic fire risk assessment and risk-based decision making in buildings". Proceedings of the 11th International Conference on Application of Statistics and Probability in Civil Engineering. ICASP11. August 1-4. Zurich, Switzerland.

6. Della Corte, G., Landolfo, R., Mazzolani, F.M. 2003. "Post-earthquake fire resistance of moment resisting steel frames," Fire Safety Journal, 38: 593-612.

7. Dumont, F., Wellens, E., Gernay, T., Franssen, J.M. 2016. "Loadbearing capacity criteria in fire resistance testing". Materials and Structures, 10.1617/s11527-016-0807-7.

8. Elhami Khorasani, N., Gardoni, P., Garlock, M.E.M. 2015a. "Probabilistic Fire Analysis: Material Models and Evaluation of Steel Structural Members," Journal of Structural Engineering, ASCE, 141(12).

9. Elhami Khorasani, N., Garlock, M.E.M. 2015. "Overview of Fire Following Earthquake: Historical Events and Community Responses". Tentatively accepted for publication in the Int'l Journal of Disaster Resilience in the Built Environment.

10. Elhami Khorasani, N., Garlock, M.E.M., Gardoni, P. 2014. "Fire Load: Survey Data, Recent Standards, and Probabilistic Models for Office Buildings," Journal of Engineering Structures, 58, 152-165.

11. Elhami Khorasani, N., Garlock, M.E.M., Quiel, S.E. 2015b. "Modeling Steel Structures in OpenSees: Enhancements for Fire and Multi-Hazard Probabilistic Analysis," Journal of Computers and Structures, 157: 218-231.

12. Elhami Khorasani, N., Gernay, T., Garlock, M.E.M. 2015c. "Modeling post-earthquake fire ignitions in a community". Submitted to Fire Safety Journal.

13. Gernay, T., Elhami Khorasani, N., Garlock, M.E.M. 2016. "Fire fragility curves for steel buildings in a community context: A methodology". Engineering Structures, 113: 259-276.

14. Guo, Q., Jeffers, A. 2014. "Finite Element Reliability Analysis of Structures Subject to Fire". Journal of Structural Engineering, ASCE. published online on July 16.

15. Guo, Q., Kaihang, S., Zili J., Jeffers, A. 2013. "Probabilistic Evaluation of Structural Fire Resistance". Fire Technology. 49(3): 793-811.

16. Hay, A., Martyn, N., Palacio, A.G. 2014. "Planning Resilient Communities". Proceedings of the Infrastructure Security Partnership, Critical Infrastructure Symposium. Colorado Springs. April 7-9.

17. Jiang, J., Jiang, L., Kotsovinos, P., Zhang, J., Usmani, A., McKenna, F., Li, G. 2015. "OpenSees Software Architecture for the Analysis of Structures in Fire," Journal of Computing in Civil Engineering, ASCE, 29(1).

18. Lange, D., Devaney, S., Usmani, A. 2014. “An application of the PEER performance based earthquake engineering to structures in fire". Engineering Structures. 66: 100-115.

19. NIBS: National Institute of Buildings Sciences. (1999). HAZUS, earthquake loss estimation technology, FEMA, Washington, DC.

20. Ronagh, H.R., Behnam B. 2012. "Investigating the effect of prior damage on the post-earthquake fire resistance of reinforced concrete portal frames". International Journal of Concrete Structures and Materials. 6: 209-220.

21. SAC Joint Venture. September. 2000. "FEMA 355C: State of the Art Report on System Performance of Steel Moment Frames Subject to Earthquake Ground Shaking," Federal Emergency Management Agency.

22. Usmani, A.S., Chung, Y.C., Torero, J.L. 2003. "How did the WTC towers collapse: a new theory," Fire Safety Journal, 38: 501-533.

23. Zaharia, R., Pintea, D. 2009. "Fire after earthquake analysis of steel moment resisting frames". International Journal of Steel Structures. KSSC 9: 275-284.

24. Scawthorn, C.R., Eidinger, J.M., Schiff, A.J. 2005. Fire Following Earthquake. Technical Council on Lifeline Earth- quake Engineering. Monograph No. 26. Published by the American Society of Civil Engineers. Reston.

25. Shome, N., Cornell, C.A. 1999. Probabilistic seismic demand analysis of nonlinear structures. Reliability of Marine Structures. Rep. No. RMS-35. Dept. of Civil and Environmental Engineering. Stanford University. Stanford, California. 26. Pant, R. 2009. Advances in Artificial Ground Motion Generation. Masters Thesis. Department of Civil and Environmental Engineering. Princeton University. Princeton, NJ. 